\title{
Inhibition of Platelet-aggregating Activity in Thrombotic Thrombocytopenic Purpura Plasma by Normal Adult Immunoglobulin $\mathbf{G}$
}

\author{
Eric C.-Y. Lian, Paul T. K. Mui, Farooq A. Siddiqui, \\ Aidan Y. Y. Chiu, and Lillian L. S. Chiu \\ Department of Medicine, Veterans Administration Medical \\ Center, and the Hemophilia and Thrombosis Center, Center for \\ Blood Diseases, University of Miami School of Medicine, \\ Miami, FL 33125
}

bstract. Plasma from patients with thrombotic thrombocytopenic purpura (TTP) caused the aggregation of autologous and homologous platelets, an effect which was inhibited by normal plasma. IgG purified from seven normal adults at a concentration of $0.7 \mathrm{mg} /$ $\mathrm{ml}$ completely inhibited the platelet aggregation induced by plasma obtained from two TTP patients with active disease. The inhibition of platelet aggregation by human adult IgG was concentration dependent, and the inhibitory activity of human IgG was neutralized by rabbit antihuman IgG. Fab fragments inhibited the TTP plasmainduced platelet aggregation as well as intact IgG, whereas Fc fragments had no effect. Platelet aggregation caused by ADP, collagen, epinephrine, or thrombin was not affected by purified human IgG. The prior incubation of IgG with TTP plasma caused a significantly greater reduction of platelet aggregation by TTP plasma than that of $\mathrm{IgG}$ and platelet suspension, suggesting that the IgG inhibits TTP plasma-induced platelet aggregation through direct interaction with platelet aggregating factor in TTP plasma.

IgG obtained initially from five infants and young children under the age of $4 \mathrm{yr}$ did not possess any inhibitory activity. When one of the children reached $3 \mathrm{yr}$ of age, his IgG inhibited the aggregation induced by one TTP plasma, but not that caused by another plasma. The IgG procured from the same boy at $4 \mathrm{yr}$ of age inhibited

This work was presented in part at the Annual Meeting of the Federation of American Societies for Experimental Biology, Atlanta, GA, April 1981, and the American Society of Hematology, Washington, DC, December 1982.

Received for publication 10 November 1981 and in revised form 4 October 1983.

The Journal of Clinical Investigation, Inc.

Volume 73, February 1984, 548-555 the aggregation induced by both TTP plasmas. The IgG purified from the TTP plasma during active disease failed to inhibit the aggregation caused by the same plasma. After recovery, however, the IgG effectively inhibited aggregation. These observations suggest that platelet-aggregating factors present in the TTP plasma are heterogeneous in nature and that the IgG present in the normal adult plasma, which inhibits the TTP plasma-induced platelet aggregation, may be partially responsible for the success of plasma infusion therapy in TTP.

\section{Introduction}

Thrombotic thrombocytopenic purpura (TTP) ${ }^{1}$ is a syndrome manifested with thrombocytopenia, microangiopathic hemolytic anemia, neurologic signs, fever, and renal dysfunction (1). Clinical studies have shown that a majority of patients with TTP responded favorably to exchange transfusions with whole blood (2). The original rationale for exchange transfusion was to remove a postulated "toxic material." Recently, it has been shown that most patients with typical symptoms of TTP responded successfully with plasma infusion (3). This suggested that the deficiency of certain normal plasma component(s) may contribute to the development of the disease. It has been demonstrated that TTP plasma induced the aggregation of washed platelets obtained from normal donors as well as TTP patients during remission. This platelet-aggregating activity was not affected by hirudin, diisopropylfluorophosphate, or heparin in the presence of normal amounts of antithrombin III, but was reduced significantly when the TTP plasma was preincubated with normal plasma (4).

Recently, we succeeded in isolating from normal plasma and purifying to homogeneity an inhibitor which inactivated the ability of TTP plasma to aggregate platelets $(5,6)$. Because the physicochemical properties of that inhibitor were similar to

1. Abbreviations used in this paper: TTP, thrombotic thrombocytopenic purpura. 
those of IgG, such as the elution pattern on DEAE Sephadex chromatography, the molecular weight, and the binding to protein $A$, it was suspected that the purified inhibitory protein is IgG. Here we report that the platelet aggregation induced by TTP plasma is indeed inhibited by whole IgG and its Fab fragments from adult sera.

\section{Methods}

Materials. Epinephrine bitartrate, ADP, collagen type II, EDTA, 2mercaptoethanol, sodium dodecyl sulfate (SDS), and papain were obtained from Sigma Chemical Co., St. Louis, MO. Agarose, Sephadex G-200, DEAE Sephadex A-50, and protein A-Sepharose CL-4B were purchased from Pharmacia Fine Chemicals, Piscataway, NJ. Acrylamide, bisacrylamide, DEAE Affi-Gel Blue, Bio-Gel A-5 m (200-400 mesh), Bio-Gel A-0.5 m (200-400 mesh), Coomassie brilliant blue R-250, and high and low molecular weight protein markers (myosin, $\beta$-galactosidase, phosphorylase, bovine serum albumin (BSA), ovalbumin, carbonic anhydrase, and soybean trypsin inhibitor) were supplied by Bio-Rad Laboratories, Richmond, CA. DEAE cellulose (DE 52) was obtained from Whatman Ltd., Springfield Mill, Maidstone Kent, England. Commercial rabbit antisera against Fab, and $\mathrm{Fc}$ were obtained from Behring Diagnostics, Somerville, NJ. Human fibrinogen was purchased from Kabi Group, Stockholm, Sweden; human thrombin from Ortho Diagnostics, Inc., Raritan, NJ; aluminum hydroxide (Amphojel) from Wyeth Lab., Philadelphia, PA; human albumin (25\%) from Armour Pharmaceutical Co., Kankakee, IL; and citrate phosphate dextrose blood pack from Fenwall Laboratories, Inc., Morton Grove, IL. Other chemicals are of analytical grade.

TTP plasmas from two patients were generously provided by Dr. J. Ansell, whose patient was reported elsewhere (7), and Dr. William Rymer, whose patient also had classic manifestations of thrombocytopenia, Coombs negative microangiopathic hemolytic anemia, fluctuating neurologic signs, renal abnormalities, and fever, and who responded to plasma exchange. Both plasmas were prepared by collection of blood into PA-10 Blood-Pack units containing $75 \mathrm{ml}$ citrate dextrose solution USP formula A (Fenwall Laboratories, Inc.) and centrifugation at 2,400 $g$ for $20 \mathrm{~min}$ at $4^{\circ} \mathrm{C}$. The supernatant plasma was further spun at 10,000 $g$ for $10 \mathrm{~min}$ at $4^{\circ} \mathrm{C}$. The platelet-poor plasma was divided into small aliquots and stored at $-70^{\circ} \mathrm{C}$ until use.

The normal adult sera were obtained from consenting normal healthy laboratory personnel, after incubation of whole blood at $37^{\circ} \mathrm{C}$ for $2 \mathrm{~h}$ or through conversion of thawed citrated plasma by addition of $\mathrm{CaCl}_{2}$ (1 part of $0.5 \mathrm{M} \mathrm{CaCl}_{2}$ to 30 parts of plasma), and incubation at $37^{\circ} \mathrm{C}$ for $2 \mathrm{~h}$. The sera from infants and children were converted from thawed residual citrated plasmas obtained from the clinical laboratory, which were stored at $-70^{\circ} \mathrm{C}$.

TTP plasma-induced platelet aggregation studies. The platelet aggregation was performed as described previously $(4,8)$. Briefly, platelets were separated and washed by using an albumin density gradient method modified from that reported by Walsh et al. (9). The washed platelets were suspended in Tris saline buffer, $\mathrm{pH} 7.4$, containing $0.133 \mathrm{M} \mathrm{NaCl}$, $0.015 \mathrm{M}$ Tris- $\mathrm{Cl}, 0.005 \mathrm{M} \mathrm{KCl}$, and $0.001 \mathrm{M} \mathrm{MgCl}_{2}$, and adjusted to a concentration of $750,000 / \mathrm{mm}^{3} .0 .4 \mathrm{ml}$ of TTP plasma, either undiluted or diluted with Tris saline buffer, was incubated in a cell at $37^{\circ} \mathrm{C}$ in a Chrono-log platelet aggregometer by using a $609-\mathrm{nm}$ red filter. To this, $0.1 \mathrm{ml}$ of platelet suspension was added. The percent decrease of optical density resulting from platelet aggregation was recorded. As shown in Fig. $1 A$ and $B$, the magnitude of platelet aggregation was dependent upon the concentration of TTP plasma.
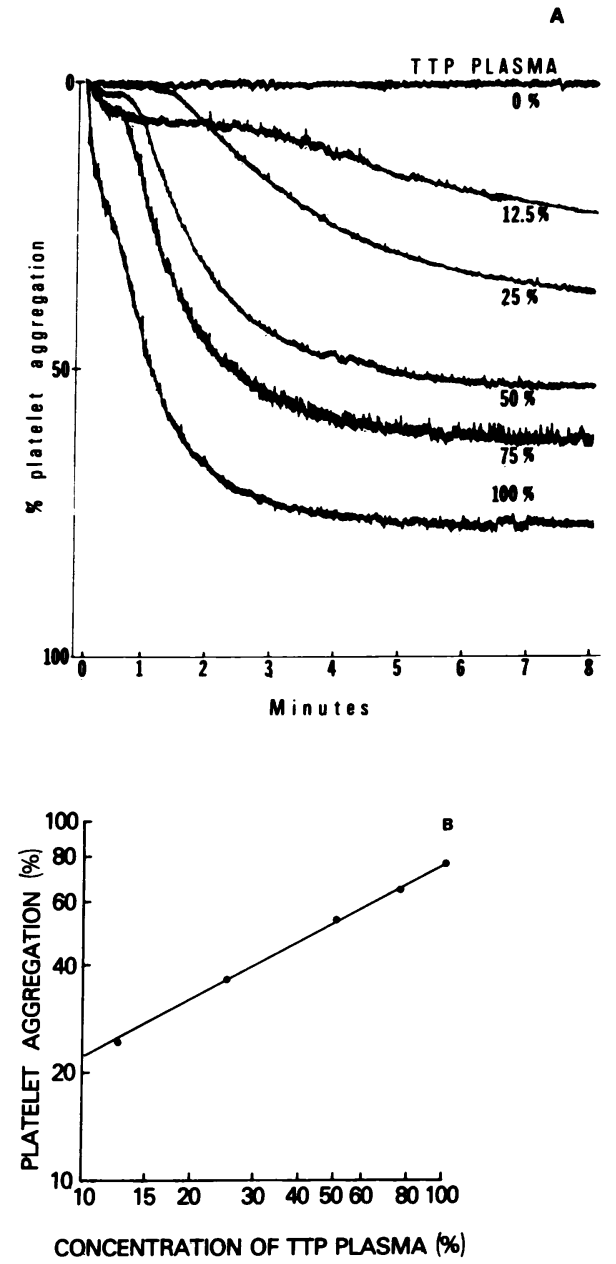

Figure 1. Effect of varying concentrations of TTP plasma on the platelet aggregation. $(A)$ shows the tracings of platelet aggregation induced by the different concentrations of TTP plasma in a volume of $0.4 \mathrm{ml}$, to which $0.1 \mathrm{ml}$ of platelet suspension $\left(750,000 / \mathrm{mm}^{3}\right)$ was added. The platelet aggregation was recorded up to $8 \mathrm{~min}$. In $(B)$ the percent of platelet aggregation at $8 \mathrm{~min}$ from $(A)$ were plotted against the various concentrations of TTP plasma on a double logarithmic scale.

Method to assay TTP platelet-aggregating factor inhibitory activity. A mixture of $0.2 \mathrm{ml}$ of TTP plasma and $0.2 \mathrm{ml}$ of IgG fraction (or buffer) was preincubated in a cell at $37^{\circ} \mathrm{C}$ for $1 \mathrm{~h}$ and then placed in a platelet aggregometer. To this, $0.1 \mathrm{ml}$ of platelet suspension was added. The inhibitory activity was measured by a decrease in the magnitude of platelet aggregation caused by TTP plasma in the presence of normal plasma fraction or IgG as compared with that in the presence of buffer alone at $8 \mathrm{~min}$ after addition of platelet suspension.

Purification of $\operatorname{IgG}$ and $\operatorname{Ig} G$ subclasses. Between 4 and $20 \mathrm{ml}$ of human or rabbit serum was dialyzed overnight against three changes of 100 vol of $0.02 \mathrm{M}$ potassium phosphate, $\mathrm{pH} 8.0$, containing $0.02 \%$ $\mathrm{NaN}_{3}$. The dialyzed serum was loaded onto a $1.6 \times 62-\mathrm{cm}$ DEAE AffiGel Blue column and eluted with the same buffer. The flow-through 


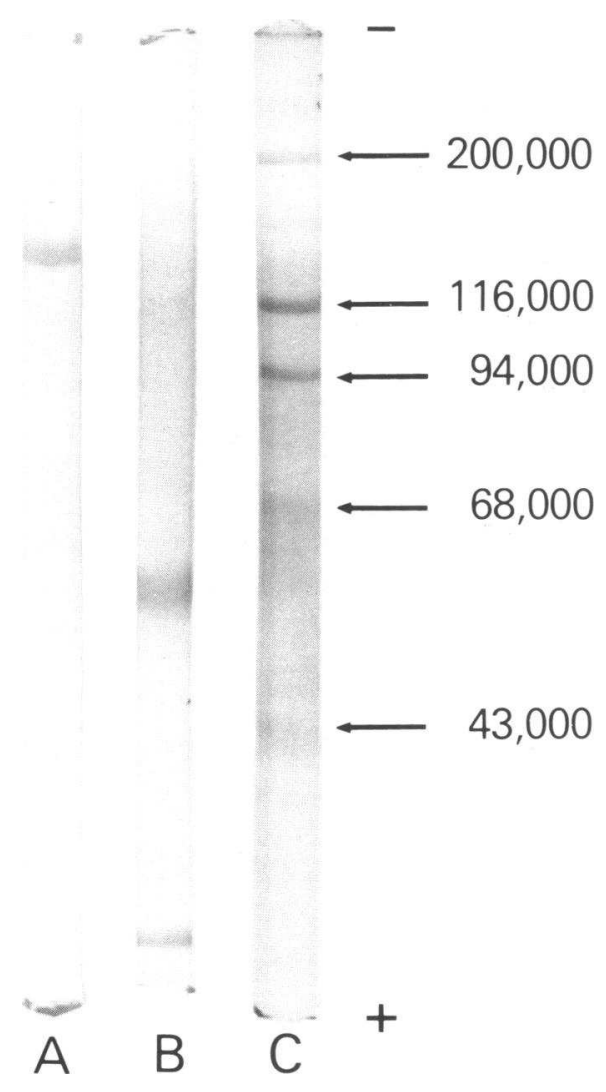

Figure 2. The electrophoretic pattern of purified IgG on a 7.5\% SDSpolyacrylamide gel under nonreduced $(A)$ and reduced $(B)$ conditions. 10 and $20 \mu \mathrm{g}$ of protein were respectively applied to the gels. Arrows indicate the molecular weight of the marker proteins: myosin, 200,000; $\beta$-galactosidase, 116,000; phosphorylase, 94,000; BSA, 68,000 ; and ovalbumin, 43,000.

protein peak fractions were pooled and concentrated to between 1 and $1.5 \mathrm{ml}$ by using polyethylene glycol 20,000 , dialyzed overnight against two changes of $500 \mathrm{ml}$ of $0.05 \mathrm{M}$ phosphate buffer, pH 7.0, containing $0.02 \% \mathrm{NaN}_{3}$. After dialysis, the sample was loaded onto a $1.5 \times 70-\mathrm{cm}$ Bio-Gel A-0.5 m (200-400 mesh) column and eluted with the same buffer at $18 \mathrm{ml} / \mathrm{h}$. Only one protein peak was obtained. Fractions under the peak were pooled and passed through a $1 \times 15-\mathrm{cm}$ protein ASepharose CL-4B column. The column was washed with $0.05 \mathrm{M}$ sodium phosphate, pH 7.0, containing $0.02 \% \mathrm{NaN}_{3}$ until the absorbance at 280 $\mathrm{nm}$ became zero. The IgG bound to the protein A-Sepharose CL-4B column was eluted with $0.1 \mathrm{M}$ glycine buffer containing $0.02 \% \mathrm{NaN}_{3}$, pH 3.0. The IgG fractions having more than 0.5 O.D. at $280 \mathrm{~nm}$ were pooled, dialyzed against distilled water, lyophilized, and stored at $-70^{\circ} \mathrm{C}$. The purity of IgG was confirmed by SDS-polyacrylamide electrophoresis under nonreducing and reducing conditions (Fig. 2). For the purification of rabbit IgG, the Bio-Gel A-0.5 m chromatography was skipped.

IgG subclasses $\left(\operatorname{IgG}_{1}, \operatorname{IgG}_{2}\right.$, and $\left.\operatorname{IgG}_{3}\right)$ were separated and isolated as described by Duhamel et al. (10).

Preparation of human Fab and Fc fragments. The Fab and Fc fragments were prepared by papain digestion by a modification of the method described by Porter (11). Briefly, $40 \mathrm{mg}$ of purified human $\lg \mathrm{G}$ containing TTP platelet-aggregating factor inhibitory activity was dissolved in $2 \mathrm{ml}$ of $0.005 \mathrm{M}$ potassium phosphate buffer, $\mathrm{pH} 6.5$, containing $0.01 \mathrm{M}$ cysteine and $0.002 \mathrm{M}$ EDTA. To this, $0.8 \mathrm{mg}$ of papain was added and the mixture was incubated at $37^{\circ} \mathrm{C}$ for $4 \mathrm{~h}$. The papain digest was dialyzed overnight against $0.005 \mathrm{M}$ phosphate buffer, $\mathrm{pH} 8.0$, to remove cysteine and EDTA. The dialyzed fraction was loaded onto a 2.5 $\times$ 18.5-cm DEAE-cellulose column, which was equilibrated with 0.005 $M$ potassium phosphate buffer, $\mathrm{pH} 8.0$. After washing with $150 \mathrm{ml}$ of the same buffer, the column was then eluted with $500 \mathrm{ml}$ of linear gradient from $0.005 \mathrm{M}$ to $0.3 \mathrm{M}$ phosphate buffer, $\mathrm{pH} 8.0$, at $20 \mathrm{ml} / \mathrm{h}$ in 5-ml fractions. The protein peak containing Fab fragments appeared in the flow through. The protein peak containing Fc fragments was eluted in the gradient.

The Fab fragments were further purified by adsorption with protein A-Sepharose CL-4B to remove traces of whole and partially cleaved IgG. Fractions under the first peak of DEAE-cellulose chromatography were pooled, concentrated with polyethylene glycol 20,000 , and dialyzed against $0.05 \mathrm{M}$ potassium phosphate buffer, $\mathrm{pH}$ 8.0. The dialyzed material was loaded onto a $1 \times 7.5-\mathrm{cm}$ protein A-Sepharose CL-4B column, which was equilibrated with $0.05 \mathrm{M}$ of potassium phosphate, $\mathrm{pH}$ 8.0. The column was washed with the same buffer until the absorbance became zero at $280 \mathrm{~nm}$. The Fab fragments appeared in the flow through while the whole IgG and Fc fragments were bound to the column. The flow-through fractions were pooled, concentrated with polyethylene glycol 20,000 , and stored at $-70^{\circ} \mathrm{C}$.

The Fc fragments from the DEAE-cellulose chromatography were further purified on Sephadex G-200 to remove the whole IgG. Fractions in the second protein peak from the DEAE-cellulose chromatography were concentrated with polyethylene glycol 20,000 , and dialyzed against $0.05 \mathrm{M}$ potassium phosphate buffer, $\mathrm{pH}$ 8.0. The concentrated material $(1.0 \mathrm{ml})$ was loaded onto a $1 \times 60-\mathrm{cm}$ Sephadex G-200 column preequil-

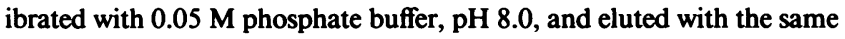
buffer at $10 \mathrm{ml} / \mathrm{h}$ in $1-\mathrm{ml}$ fractions. The $\mathrm{Fc}$ fragments were eluted in a single symmetrical peak or two peaks, depending on the degree of digestion. The fractions of the protein peak containing $\mathrm{Fc}$ fragments were pooled, concentrated, and stored at $-70^{\circ} \mathrm{C}$.

The purity of Fab (Fig. 3) and Fc fragments (not shown) was confirmed by $10 \%$ SDS-polyacrylamide gel electrophoresis and immunodiffusion studies against commercial anti-Fab and anti-Fc antisera. Before the platelet aggregation studies, the Fab and Fc fragments were thoroughly dialyzed against the platelet assay buffer.

Preparation of antisera against human IgG. Antisera to the human IgG were prepared by injecting New Zealand White rabbits subcutaneously with a mixture of $1 \mathrm{ml}$ purified IgG containing 40-200 $\mu \mathrm{g}$ and $1 \mathrm{ml}$ of complete Freund's adjuvant weekly for 2 wk followed by weekly injections of IgG for another $2 \mathrm{wk} .4 \mathrm{wk}$ after the last injection, the rabbits were bled and antisera were collected.

Neutralization of the inhibitory activity of human IgG by rabbit antihuman IgG. Just prior to the neutralization studies, the rabbit IgG against human IgG was dissolved in Tris-saline buffer, $\mathrm{pH} 7.4$, and passed through a $0.9 \times 18-\mathrm{cm}$ column of Bio-Gel A-5 m (200-400 mesh) at $30 \mathrm{ml} / \mathrm{h}$ to remove IgG aggregates. $0.2 \mathrm{ml}$ of rabbit anti-human IgG at various concentrations was mixed with $0.2 \mathrm{ml}$ of purified human $\operatorname{IgG}(2 \mathrm{mg} / \mathrm{ml})$, and incubated for $2 \mathrm{~h}$ at $37^{\circ} \mathrm{C}$. The incubation mixture was then centrifuged at $48,200 \mathrm{~g}$ for $1 \mathrm{~h} .0 .2 \mathrm{ml}$ of the supernatant was removed and incubated with $0.2 \mathrm{ml}$ of TTP plasma at $37^{\circ} \mathrm{C}$ for $1 \mathrm{~h}$. Then, $0.1 \mathrm{ml}$ of platelet suspension was added and platelet aggregation was recorded. Preimmune rabbit IgG did not affect platelet aggregation in the presence or absence of TTP plasma. 


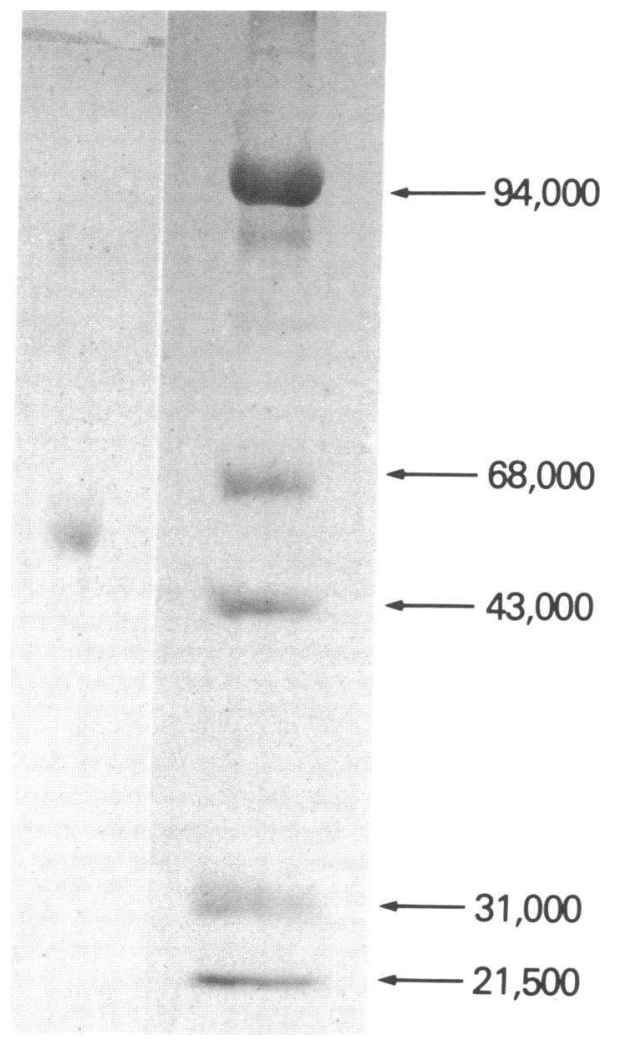

Figure 3. The electrophoretic pattern of purified Fab fragments on $10 \%$ SDS-polyacrylamide gel under nonreduced condition. $8.0 \mu \mathrm{g}$ protein was applied. Arrows indicate the molecular weight of the marker proteins: phosphorylase, 94,000; BSA, 68,000; ovalbumin, 43,000; carbonic anhydrase, 31,000; soybean trypsin inhibitor, 21,500 .

Studies of the effects of the human IgG on ADP epinephrine, collagen, and thrombin-induced platelet aggregation. A mixture of $0.05 \mathrm{ml}$ of epinephrine, ADP, collagen, or thrombin, $0.1 \mathrm{ml}$ of $2.5 \mathrm{mg} / \mathrm{ml}$ fibrinogen, $0.2 \mathrm{ml}$ of $2.5 \mathrm{mg} / \mathrm{ml}$ human IgG, and $0.05 \mathrm{ml}$ of Tris-saline buffer, $\mathrm{pH}$ 7.4 , was incubated in a cell for $1 \mathrm{~h}$. After it was transferred to the platelet aggregometer, $0.1 \mathrm{ml}$ of platelet suspension, which we prewarmed to $37^{\circ} \mathrm{C}$, was added. The change in optical density was recorded. Human fibrinogen, human IgG, epinephrine bitartrate, ADP, and thrombin were prepared in Tris-saline buffer, pH 7.4. Collagen type II was prepared as described by Hovig (12) and suspended in the same buffer. The final concentration for ADP was 10 and $50 \mu \mathrm{M}$; epinephrine, 10 and $50 \mu \mathrm{M}$ collagen, 6 and $12 \mu \mathrm{g} / \mathrm{ml}$; and thrombin, 0.02-0.2 units $/ \mathrm{ml}$. A control study without human IgG was always run at the same time.

Protein concentration. Protein concentration was measured by the method of Lowry et al. (13) except for fractions eluted from columns, where absorption at $280 \mathrm{~nm}$ was used.

SDS-polyacrylamide gel electrophoresis. Proteins were electrophoresed on slab gels containing 7.5 or $10 \%$ SDS acrylamide according to the method of Weber and Osborn (14). Gels were stained with Coomassie brilliant blue R-250. Myosin, $\beta$-galactosidase, phosphorylase, BSA, ovalbumin, carbonic anhydrase, and soybean trypsin inhibitor were used as the molecular weight markers.

\section{Results}

Inhibition of the platelet-aggregating activity of TTP plasma by IgG obtained from normal human subjects. The IgG purified from seven normal adults at the concentration of $0.7 \mathrm{mg} / \mathrm{ml}$ completely inhibited the platelet aggregation induced by plasma obtained from two TTP patients during disease (Table I). The inhibition of platelet aggregation by IgG was concentration dependent (Fig. 4) and the inhibitory activity of IgG was neutralized by rabbit antibodies against human IgG (Fig. 5). The preincubation of IgG with TTP plasma caused a significantly greater reduction of platelet aggregation by TTP plasma than that of IgG and platelet suspension (Fig. 6).

After digestion of IgG-containing inhibitory activity with papain, the effect of IgG fragments was studied. It was found that Fab fragments inhibited the TTP plasma-induced platelet aggregation as the whole IgG, whereas Fc fragments had no effect (Fig. 7).

The IgG obtained initially from five infants and young children under the age of $4 \mathrm{yr}$ did not have any significant inhibitory activity. When one of the children reached the age of $3 \mathrm{yr}$, his IgG inhibited the aggregation induced by one plasma but not that induced by another plasma. The IgG of the same boy at the age of 4 inhibited the aggregation induced by either plasma (Table II).

In one study, the $\operatorname{IgG}_{1}, \mathrm{IgG}_{2}$, and $\mathrm{IgG}_{3}$ separated by protein A chromatography all possessed almost the same amounts of inhibitory activity when the same concentration was used.

Effect of IgG purified from the TTP patients on the TTP plasma-induced platelet aggregation. At $0.7 \mathrm{mg} / \mathrm{ml}$, the IgG obtained from patient 1 during disease did not have any inhibitory activity on the aggregation induced by either patient's

Table I. Inhibitory Activity of IgG Obtained from Normal Adults

\begin{tabular}{llll}
\hline & & \multicolumn{2}{c}{$\begin{array}{c}\text { \% inhibition of platelet aggregation } \\
\text { induced by: }\end{array}$} \\
\cline { 3 - 4 } Sources of IgG & Age & TTP plasma 1 & TTP plasma 2 \\
\hline & $y r$ & & \\
1 & 45 & 100 & 98 \\
2 & 25 & 100 & 100 \\
3 & 24 & 100 & 100 \\
4 & 40 & 100 & 100 \\
5 & 39 & 100 & 100 \\
6 & 45 & 100 & 100 \\
7 & 45 & 95 & 100 \\
\hline
\end{tabular}

A mixture of $0.2 \mathrm{ml}$ TTP plasma and $0.2 \mathrm{ml}$ of Tris-saline buffer solution containing $0.35 \mathrm{mg}$ of $\mathrm{IgG}$ was incubated for $1 \mathrm{~h}$ at $37^{\circ} \mathrm{C}$. Then, $0.1 \mathrm{ml}$ of platelet suspension $\left(750,000 / \mathrm{m}^{3}\right)$ was added. The percent of platelet aggregation was recorded. In the absence of IgG, TTP plasma 1 and 2 caused 32 and $20 \%$ platelet aggregation, respectively. 


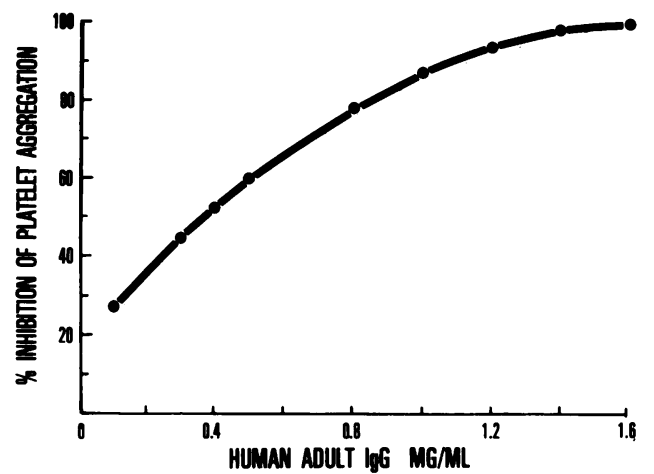

Figure 4. Inhibition of TTP plasma-induced platelet aggregation by various concentrations of human adult $\mathrm{IgG} .0 .2 \mathrm{ml}$ of purified $\mathrm{IgG}$ at various concentrations or buffer was incubated with $0.2 \mathrm{ml}$ of TTP plasma at $37^{\circ} \mathrm{C}$ for $1 \mathrm{~h}$. Then, $0.1 \mathrm{ml}$ of washed platelet suspension $\left(750,000 / \mathrm{mm}^{3}\right)$ was added to the mixture and the magnitude of platelet aggregation was recorded. The inhibition is expressed by the percent depression of platelet aggregation in the presence of human IgG as compared with that in the absence of human IgG.

plasma during disease, whereas the IgG obtained after recovery inhibited the aggregation caused by both patients' plasma during disease (Table III). At the same concentration, the IgG obtained from patient 2 during disease inhibited the aggregation induced by the first patient's plasma, but not that caused by her own plasma. After recovery, the IgG inhibited the platelet aggregation induced by either plasma.

Effect of IgG from normal adults on the platelet aggregation induced by various agents. It was found that the human IgG (which inhibited TTP plasma-induced aggregation), at the con-

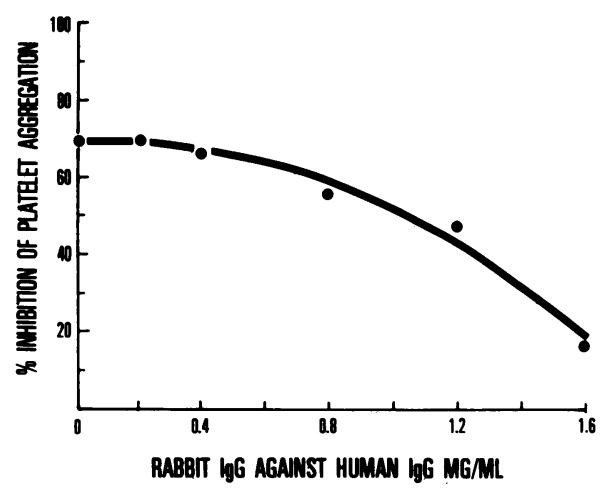

Figure 5. Neutralization titration of a fixed amount of the human IgG inhibitory activity by the increasing concentrations of rabbit anti-human IgG. The increasing amounts of antibodies against human IgG in $0.2 \mathrm{ml}$ were incubated with the fixed amount of human $\operatorname{IgG}(400 \mu \mathrm{g})$ for $2 \mathrm{~h}$ at $37^{\circ} \mathrm{C}$. The incubation mixture was then spun at $48,200 \mathrm{~g}$ for $1 \mathrm{~h}$, and the precipitate was discarded. The residual inhibitory activity in the supernatant was assayed by incubating with $0.2 \mathrm{ml}$ of TTP plasma as described in Fig. 4. The preimmunized IgG did not have any effect on the platelet aggregation.

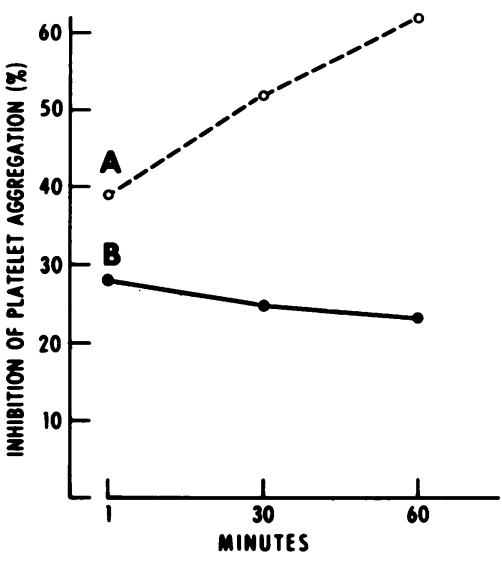

Figure 6. Effect of preincubation of human adult IgG with TTP plasma or platelets, respectively, on the TTP plasma-induced platelet aggregation. In experiment $\mathrm{A}$, a mixture of $0.2 \mathrm{ml}$ of $1.25 \mathrm{mg} / \mathrm{ml} \mathrm{hu}$ man adult IgG (or buffer) and $0.2 \mathrm{ml}$ of TTP plasma was incubated at $37^{\circ} \mathrm{C}$ for 1,30 , and $60 \mathrm{~min}$ before $0.1 \mathrm{ml}$ of platelet suspension was added. In experiment $B$, a mixture of $0.2 \mathrm{ml}$ of $1.25 \mathrm{mg} / \mathrm{ml} \mathrm{hu}$ man adult IgG (or buffer) and $0.1 \mathrm{ml}$ of platelet suspension was incubated at $37^{\circ} \mathrm{C}$ for 1,30 , and $60 \mathrm{~min}$ before the addition of $0.2 \mathrm{ml}$ of TTP plasma. The percent inhibition of platelet aggregation was calculated as described in the legend of Fig. 4.

centration of $1 \mathrm{mg} / \mathrm{ml}$, did not affect the platelet-aggregating activity of thrombin, collagen, epinephrine, or ADP.

\section{Discussion}

Currently, the etiology and pathogenesis of TTP are poorly understood. Pathologically, TTP is characterized by deposition

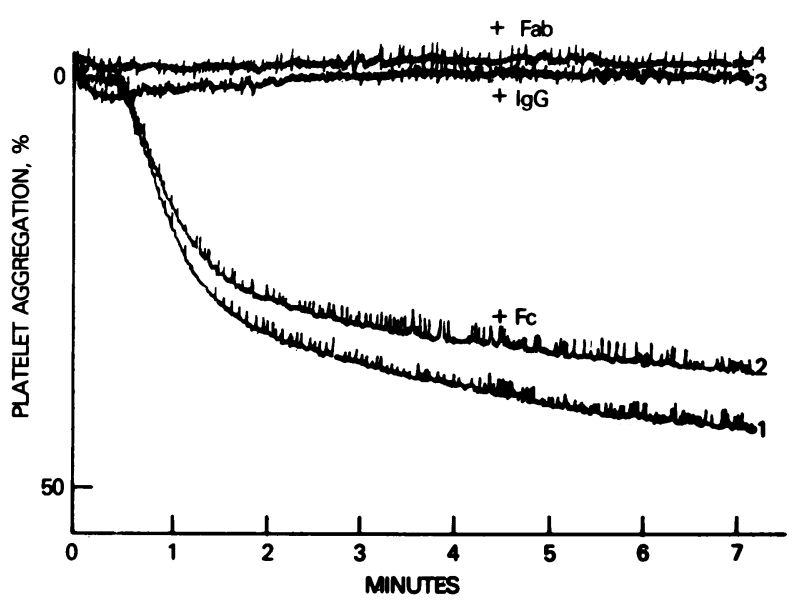

Figure 7. Inhibition by Fab but not Fc fragments on the TTP plasma-induced platelet aggregation. $0.2 \mathrm{ml}$ of TTP plasma was preincubated with either buffer (1), Fc (2), IgG (3), or Fab fraction (4) for $1 \mathrm{~h}$ at $37^{\circ} \mathrm{C}$ before addition of platelet suspension. The final concentration of $\operatorname{IgG}, \mathrm{Fab}$, and $\mathrm{Fc}$ in the reaction mixture was 0.7 $\mathrm{mg} / \mathrm{ml}$. 
Table II. Inhibitory Activity of IgG Obtained from Infants and Children

\begin{tabular}{lrcc}
\hline & & \multicolumn{2}{c}{$\begin{array}{c}\text { \% inhibition of platelet aggregation } \\
\text { induced by: }\end{array}$} \\
\cline { 3 - 4 } Sources of IgG & & & \\
\cline { 2 - 4 } & Age & TTP plasma 1 & TTP plasma 2 \\
1 & $m o$ & & \\
2 & 7 & 0 & 0 \\
3 & 9 & 0 & 3 \\
4 & 21 & 8 & 4 \\
5 & 44 & 4 & 0 \\
& 5 & 6 & 0 \\
& 16 & 11 & 0 \\
& 44 & 95 & 100 \\
\hline
\end{tabular}

The experimental conditions were the same as that described under Table I. In the absence of IgG, TTP plasma 1 and 2 caused 26 and $20 \%$ platelet aggregation, respectively.

of hyaline thrombi composed of mainly platelets with some fibrin in the arterioles and capillaries. Several hypotheses have been postulated to explain the pathogenic mechanism. These include: $(a)$ the presence of a circulating toxin, antibody, or immune complexes, which promote microthrombus formation $(2,15,16) ;(b)$ injury of small vessels which triggers platelet adhesion and aggregation $(17,18) ;(c)$ a defect in the fibrinolytic control mechanism (19); and (d) deficiency of $\mathrm{PGI}_{2}$-stimulating factor $(20,21)$ or stabilizing factor (22). Recently, our laboratory has found that TTP plasma caused the aggregation of both autologous and homologous platelets. The platelet-aggregating activity of TTP plasma was reduced as a function of time when TTP plasma was preincubated with normal plasma (4), suggesting that certain substance(s) in the normal plasma (which is deficient in TTP plasma) may inactivate a certain aggregating factor in the TTP plasma directly, interfere with the interaction between the TTP platelet-aggregating factor and platelets, or act through some other mechanisms.

We have reported the purification of a protein from normal plasma which inhibited the TTP plasma-induced platelet aggregation. The physicochemical properties of that inhibitor were similar to those of IgG, such as the elution pattern in the DEAESephadex chromatography, the molecular weight and subunits, and the binding to protein $A(5,6)$; therefore, the inhibitor was suspected to be IgG. This was confirmed by immunodiffusion studies by the demonstration that commercial rabbit antiserum against human IgG formed an identical line against the purified inhibitor and IgG (23).

The IgG purified from seven normal adults inhibited the platelet aggregation induced by two TTP plasma samples studied. After digestion with papain, the Fab fragments inhibited the aggregation but $\mathrm{Fc}$ fragments did not have any effect. The prior incubation of IgG with TTP plasma caused a significantly greater reduction of platelet aggregation than that of IgG and platelet suspension, suggesting that the IgG inhibits TTP plasma-induced platelet aggregation through a specific direct interaction with an as yet undefined platelet-aggregating factor in the TTP plasma in the fluid phase rather than on the platelet membrane. This

Table III. Effects of IgG Purified from TTP Patients on the TTP Plasma-induced Platelet Aggregation

\begin{tabular}{|c|c|c|c|c|}
\hline & \multicolumn{2}{|c|}{ TTP Plasma 1} & \multicolumn{2}{|c|}{ TTP Plasma 2} \\
\hline & $\begin{array}{l}\text { Platelet } \\
\text { aggregation }\end{array}$ & $\begin{array}{l}\text { Platelet aggregation } \\
\text { inhibition }\end{array}$ & $\begin{array}{l}\text { Platelet } \\
\text { aggregation }\end{array}$ & $\begin{array}{l}\text { Platelet aggregation } \\
\text { inhibition }\end{array}$ \\
\hline & $\%$ & $\%$ & $\%$ & $\%$ \\
\hline Buffer control & 32.0 & & 26.0 & \\
\hline \multicolumn{5}{|c|}{ Patient 1 IgG during illness } \\
\hline $0.35 \mathrm{mg} / \mathrm{ml}$ & 32.0 & 0 & 26.0 & 0 \\
\hline $0.70 \mathrm{mg} / \mathrm{ml}$ & 30.0 & 7 & 26.0 & 0 \\
\hline \multicolumn{5}{|c|}{ Patient 1 IgG after recovery } \\
\hline $0.35 \mathrm{mg} / \mathrm{ml}$ & 19.8 & 38 & 19.5 & 25 \\
\hline $0.70 \mathrm{mg} / \mathrm{ml}$ & 0.0 & 100 & 0.0 & 100 \\
\hline \multicolumn{5}{|c|}{ Patient 2 IgG during illness } \\
\hline $0.35 \mathrm{mg} / \mathrm{ml}$ & 14.1 & 56 & 26.0 & 0 \\
\hline $0.70 \mathrm{mg} / \mathrm{ml}$ & 5.4 & 83 & 24.2 & 7 \\
\hline \multicolumn{5}{|c|}{ Patient 2 IgG after recovery } \\
\hline $0.35 \mathrm{mg} / \mathrm{ml}$ & 0 & 100 & 9.1 & 65 \\
\hline $0.70 \mathrm{mg} / \mathrm{ml}$ & 0 & 100 & 0 & 100 \\
\hline
\end{tabular}


inhibition is different from the inhibition of platelet agglutination induced by ristocetin and von Willebrand factor by IgG or Fc fragments, which inhibits the platelet agglutination through its binding to platelet membrane Fc receptor (24). The inhibition of TTP plasma-induced platelet aggregation by IgG is also different from that of platelet adhesion by albumin-IgG complex (25). Apparently, the adult IgG does not require the complex formation with albumin to suppress platelet function.

The IgG obtained from normal adult sera inhibited the platelet aggregation induced by TTP plasma but IgG from five infants and children below the age of $4 \mathrm{yr}$ did not. When one of them reached the age of 3 , his IgG inhibited the aggregation induced by one TTP plasma but not that induced by another plasma. The IgG obtained when the boy became 4 yr old inhibited the aggregation induced by both plasmas. The plateletaggregating factor inhibitory activity of the IgG fraction was lacking in the disease plasma but present in the recovery plasma of patients with TTP. The seroconversion due to the increase of age and after the disease suggests that certain cases of TTP may be caused by infection, although direct evidence still needs to be sought. The IgG present in the normal plasma, which inhibits the TTP plasma-induced platelet aggregation, may be partially responsible for the effectiveness of plasma infusion therapy in TTP.

Clinically, TTP is frequently preceded by febrile upper respiratory illness or gastrointestinal symptoms (26). The disease has been shown to be associated with measles (27), influenza infection (28) or vaccination (29), coxakie B (30), herpes simplex (31), mycoplasma (32), microtatobiote (33), and meningococcal infection (34). Indeed, it has been shown that certain viruses induce platelet aggregation in vitro (35). Recently it has been shown that hemolytic uremic syndrome, a disease similar to TTP, may be associated with E. coli toxin (36), Campylobacter jejuni $(37,38)$, and bacillary dysentery (39). More recently, a pentapeptide extracted from Microcystis aeruginosa caused the microvascular thrombi in the lung, which were composed of platelets; the pulmonary thrombi formation could not be prevented by heparin, aspirin, or $\mathrm{PGI}_{2}(40)$. This observation is consistent with our previous in vitro demonstration that TTP plasma-induced platelet aggregation was not inhibited by aspirin, heparin, hirudin, or $\mathrm{PGI}_{2}(8)$. It is likely that the platelet-aggregating factors present in the plasma of certain patients with TTP are derived from infectious agents. If this hypothesis is correct, suppression or defect of host immune response may exacerbate the disease process and delay the recovery.

The IgG obtained from the 3-yr-old boy inhibited the platelet aggregation induced by the first TTP plasma but not that by the second TTP plasma. The IgG obtained from the second TTP plasma during disease inhibited the aggregation induced by first TTP plasma but not by his own plasma. This suggests that the platelet-aggregating factors present in the various TTP plasma are heterogeneous in nature, deriving from different sources.

Elevated platelet-associated IgG has been reported (41-43). The TTP plasma causes the aggregation of platelets. The IgG inactivates the platelet-aggregating activity of TTP plasma. It is conceivably possible that the interaction among the plateletaggregating factor, platelets, and IgG may give rise to the elevated platelet-associated IgG. In this case, the IgG binds to the plateletaggregating factor (which has already been attached to the platelets) rather than to the platelet membrane directly. Studies are being conducted to confirm this hypothesis.

\section{References}

1. Moschcowitz, E. 1925. An acute fibrile pleiochromic anemia with hyaline thrombosis of the terminal arterioles and capillaries: an undescribed disease. Arch. Intern. Med. 36:89-93.

2. Byrnes, J. J., and E. C.-Y. Lian. 1979. Recent therapeutic advances in thrombotic thrombocytopenic purpura. Semin. Thromb. Hemostasis. 5:199-215.

3. Bukowski, R. M., J. S. Hewlett, J. W. Harris, G. C. Hoffman, J. D. Battle, E. Silverblatt, and I. Yang. 1976. Exchange transfusions in the treatment of thrombotic thrombocytopenic purpura. Semin. Hematol. 13:219-232.

4. Lian, E. C.-Y., D. R. Harkness, J. J. Byrnes, H. Wallach, and R. Nunez. 1979. The presence of a platelet aggregating factor in the plasma of patients with thrombotic thrombocytopenic purpura and its inhibition by normal plasma. Blood. 53:333-338.

5. Lian, E. C.-Y., P. Mui, and L. Chiu. 1981. Studies on thrombotic thrombocytopenic purpura: purification and properties of platelet aggregating factor inhibitor A. VIIIth International Congress on Thrombosis and Haemostasis. 52 (Abstr.)

6. Lian, E. C.-Y., P. Mui, F. A. Siddiqui, and L. L. S. Chiu. Purification and some properties of a protein obtained from normal human plasma which inhibits the platelet aggregation induced by thrombotic thrombocytopenic purpura plasma. Thromb. Res. In press.

7. Ansell, J., R. S. Beaser, and L. Pechet. 1978. Thrombotic thrombocytopenic purpura fails to respond to fresh frozen plasma. Ann. Intern. Med. 89:647-648.

8. Lian, E. C.-Y., and N. Savaraj. 1981. Effects of platelet inhibitors on the platelet aggregation induced by plasma from patients with thrombotic thrombocytopenic purpura. Blood. 58:354-359.

9. Walsh, P. N., D. C. B. Mills, and J. G. White. 1977. Metabolism and function of human platelets washed by albumin density gradient separation. Br. J. Haematol. 36:287-296.

10. Duhamel, R. C., P. H. Schur, K. Brendel, and E. Meezan. 1979. $\mathrm{pH}$ gradient elution of human $\mathrm{IgG}_{1}, \mathrm{IgG}_{2}$, and $\mathrm{IgG}_{4}$ from protein ASepharose. J. Immunol. Methods. 31:211-217.

11. Porter, R. R. 1959. The hydrolysis of rabbit $\gamma$-globulins and antibodies with crystalline papain. Biochem. J. 73:119-126.

12. Hovig, T. 1963. Aggregation of rabbit blood platelets produced in vitro by saline "extract" of tendons. Thromb. Diath. Haemorrh. 9:248263.

13. Lowry, O. H., N. J. Rosebrough, A. L. Farr, and R. J. Randall. 1951. Protein measurement with Foline phenol reagent. J. Biol. Chem. 193:265-275.

14. Weber, K., and M. Osborn. 1969. The reliability of molecular weight determinations of dodecyl sulfate-polyacrylamide gel electrophoresis. J. Biol. Chem. 244:4406-4412.

15. Rubenstein, M. A., B. M. Kagan, M. H., MacGillviray, R. Merliss, and H. Sacks. 1959. Unusual remission is a case of thrombotic thrombocytopenic purpura syndrome following fresh blood exchange transfusion. Ann. Int. Med. 51:1409-1419. 
16. Aster, R. H. 1977. TTP: new clues to the etiology of an enigmatic disease. N. Engl. J. Med. 297:1400-1401.

17. Altschule, M. D. 1942. A rare type of acute thrombocytopenic purpura. Widespread formation of platelet thrombi in capillaries. $N$. Engl. J. Med. 227:477-479.

18. Gore, I. 1950. Disseminated arteriolar and capillary platelet thrombus: a morphologic study of its histogenesis. Am. J. Pathol. 26:155175 .

19. Kwaan, H. C. 1979. The pathogenesis of thrombotic thrombocytopenic purpura. Semin. Thromb. Hemostasis. 3:184-198.

20. Remuzzi, G., R. Misiani, G. Mecca, G. de Gaetano, and M. B. Donati. 1978. Thrombotic thrombocytopenic purpura-A deficiency of plasma factors regulating platelet-vessel-wall interaction. $N$. Engl. J. Med. 299-311.

21. Hensby, C. N., P. J. Lewis, P. Hilgard, G. J. Mufti, J. Hows, and J. Webster. 1979. Prostacyclin deficiency in thrombotic thrombocytopenic purpura. Lancet. II:748.

22. Chen, Y. C., B. McLeod, E. R. Hall, and K. K. Wu. 1981. Accelerated prostacyclin degradation in thrombotic thrombocytopenic purpura. Lancet. II:267-269.

23. Lian, E. C.-Y., P. T. K. Mui, F. A. Siddiqui, A. Y. Y. Chiu, and L. L. S. Chiu. 1983. Properties and identification of a plasma factor which inhibits the platelet aggregation by TTP plasma. Thromb. and Haemostasis. 50(1):101 (Abstr.)

24. Moore, A., G. D. Ross, and R. L. Nachman. 1978. Interaction of platelet membrane receptors with von Willebrand factor, ristocetin, and the Fc region of immunoglobulin G. J. Clin. Invest. 62:1053-1060.

25. Sharma, N. C., S. F. Mohammad, H. Y. K. Chuang, and R. G. Mason. 1981. Albumin-IgG complexes in human serum and plasma that inhibit blood platelet adhesion. Proc. Natl. Acad. Sci. USA. 78:77507753.

26. Amorosi, E. L., and J. E. Ultmann. 1966. Thrombotic thrombocytopenic purpura: report of 16 cases and review of literature. Medicine (Baltimore). 45:139-159.

27. Swaiman, K., M. Schaffhausen, and W. Krivit. 1963. Thrombotic thrombocytopenic purpura: report of an unusual clinical case and chromium $^{51}$ red cell survival studies. J. Pediatr. 60:823-829.

28. Wasserstein, A., G. Hill, S. Goldfarb, and M. Goldberg. 1981. Recurrent thrombotic thrombocytopenic purpura after viral infection. Arch. Intern. Med. 141:685-687.

29. Brown, R. C., T. E. Blecher, E. A. French, and P. J. Toghill. 1973. Thrombotic thrombocytopenic purpura and influenza vaccination (letter). Br. Med. J. 2:303.

30. Berberich, F. R., S. A. Cuene, R. L. Chard, and J. R. Hartman. 1974. Thrombotic thrombocytopenic purpura: three cases with platelet and fibrinogen survival studies. J. Pediatr. 84:503-509.
31. Myers, T. J., C. J. Wakem, E. D. Ball, and S. J. Tremont. 1980. Thrombotic thrombocytopenic purpura: combined treatment with plasmapheresis and antiplatelet agents. Ann. Intern. Med. 92:149-155.

32. Reynolds, P. M., J. M. Jackson, J. A. S. Brine, and A. B. Vivian. 1976. Thrombotic thrombocytopenic purpura-remission following splenectomy. Am. J. Med. 61:439-447.

33. Mettler, N. E. 1969. Isolation of a microtatobiote from patients with hemolytic-uremic syndrome and thrombotic thrombocytopenic purpura and from mites in the United States. N. Engl. J. Med. 281:10231027.

34. Nussbaum, M., and W. Dameshek. 1957. Transient hemolytic and thrombocytopenic episode (? acute transient thrombohemolytic thrombocytopenic purpura) with probable meningococcemia. $N$. Engl. J. Med. 256:448-450.

35. Schulz, H., and E. Landgraber. 1966. Elektronenınikroskopische Untersuchungen über die Adsorption and Phagocytose von Influenzaviren durch Thrombocyten. Klin. Wochenschr. 44:998-1006.

36. Karmali, M. A., B. T. Steele, M. Petric, and C. Lim. 1983. Sporadic cases of haemolytic-uraemic syndrome associated with faecal cytotoxin and cytotoxin-producing Escherichia coli in stools. Lancet. I:619-620.

37. Chamovitz, B. N., A. I. Hartstein, S. R. Alexander, A. B. Terry, P. Short, and R. Katon. 1983. Campylobacter jejuni-associated hemolyticuremic syndrome in a mother and daughter. Pediatrics. 71:253-256.

38. Denneberg, T., M. Friedberg, L. Holmberg, C. Mathiasen, K. O. Nilsson, R. Takolander and M. Walder. 1982. Combined plasmapheresis and hemodialysis treatment for severe hemolytic-uremic syndrome following campylobacter colitis. Acta Paediatr. Scand. 71:243245.

39. Date, A., P. Raghupathy, M. Jadhav, S. M. Pereira, and J. C. Shastry. 1982. Outcome of the haemolytic-uremic syndrome complicating bacillary dysentery. Ann. Trop. Paediatr. 2:1-6.

40. Slatkin, D. N., R. D. Stoner, W. H. Adams, J. H. Kycia, and H. W. Siegelman. 1983. A typical pulmonary thrombosis caused by a toxic cyanobacterial peptide. Sciences (New York). 220:1383-1385.

41. Morrion, J., and R. McMillan. 1977. Elevated platelet-associated IgG in thrombotic thrombocytopenic purpura. JAMA (J. Am. Med. Assoc.). 238:1944-1945.

42. Neame, P. D. 1980. Immunologic and other factors in thrombotic thrombocytopenic purpura (TTP). Semin. Thromb. Hemostasis. 6:416429.

43. Sims, P. J., and E. B. Boswell. 1981. Elevated platelet-bound $\operatorname{IgG}$ associated with an episode of thrombotic thrombocytopenic purpura. Blood. 58:682-684. 